\title{
Studying the Effect of Abundance of Natural Resources on Economic Growth
}

\author{
Abbas Amini ${ }^{1}$
}

\begin{abstract}
The tendency towards a better life and improvement of life status has always had a priority among human communities. The approach utilized by economics and specifically the growth and economic development activities refers to the improvement of the material dimension. Meanwhile, some countries are rich and some suffer from poverty. Therefore, to recognize basic growth factors and the roots of income inequality among different nations, the role of factors such as institutions, culture, and geography has been emphasized. Natural resources, from among geographical elements, are considered highly important. On the other hand, many communities that exploit a vast amount of natural resources have encountered failure in reflecting appropriate economic performances and this has often had unpleasant outcomes and resource curse has been commonly used to describe this phenomenon. Thus, the goal of the present research is to find out about the nature of resource curse phenomenon and studying different structures that affect natural resources' abundance on economic growth and development. Accordingly, some of the most important effectiveness structures of natural resources have been investigated as: long-term approaches in global prices, price fluctuations, permanent reductions in industry parts, colonialism institutions and eligibility, lack of institutions that strengthen inconsistency and chaos, cyclical nature of Netherlander disease. This study has investigated about 22 advanced countries and 61 underdeveloped and developing countries within the time period between 1996 and 2010. For both countries, we have first used group effects' meaningfulness test to recognize the nature of data (pooled or panel) and Brush-Pagan and Haussmann tests to recognize the difference between fixed and random effects, and then the research model was estimated using fixed effects method. The research findings showed that natural resources abundance, institutions, and interactions between institutions, and natural resources did not have a meaningful effect on average yearly growth rate of GDP. The final conclusion of the different strategies of effectiveness of natural resources does not mean that the need to mineral materials as the wealth necessarily would lead to the lack of the economic and political developments through many of such strategies. In return, it would be better to view the resource abundance as a two sided coin which is endowed with both advantages and risks. As much as it can be exploited for unnecessary expenses, its proper use can lead to lots of benefits.
\end{abstract}

Keywords: abundance of natural resources, resource curse, economic growth, institutions, policies

\section{Introduction}

During some recent decades, the possession of oil, natural gas, valuable mineral resources and other natural resources did not necessarily result in consistent economic growth for the countries that have had access to such resources. Many oil-oriented and plant oriented economies encountered a considerable reduction in economical growth in 1970s and 1980s. Many African countries like Angola, Nigeria, Sudan, and Congo are rich in oil, diamond, and other minerals; meanwhile they have a low level of per capita 
income and low life quality. Also in Iran the over-dependence on oil and gas income has led this inter-generations wealth to the enforcement of inflation on Iranian families (curse) through excessive consumption goods' imports although there have been some economical booms of oil exports (both before and after the Islamic Revolution in 1978) (Abrahamian, 2010). Meanwhile, the economies in East Asia such as in Japan, South Korea, Taiwan, Singapore, and Hong Kong have achieved high life standards equal to the life in west although there has been a geographical area covered with rockbound and there has not been any access to any exportable natural resources practically (Landes, 2005). Auty (2007) has entered the term resource curse clearly to describe this puzzling phenomenon in economics literature. Of course, it should be noted that all countries having access to oil wealth or other natural resources did not experience inappropriate performances compared to countries without such advantages. Also countries enriched with natural resources could succeed if they have the best exploitation of natural resources.

Up to now different modeling methods have been proposed to clarify and describe these differences in economic growth. Although traditional theories are still utilized and have supplied many viewpoints regarding the structure of economic growth, they have not been able to prepare a principal definition for the growth and such gaps in incomes between different communities. Therefore, a new route has been proposed to try to recognize major factors in growth and the roots of inequality in income between the nations which emphasize on the role of factors such as institutions (Acemoglu \& et al, 2005; Acemoglu \& Robinson, 2011), ethnic fractionalization (Easterly \& Levine, 1997), culture, and geography. From among the factors mentioned, geography entails issues such as: natural resources, climate, ecology, and topology. On the other hand, natural resources are specifically important compared to other geographical factors (and it is our priority in the rest of this research).

Alexeev and Conrad (2009) carried a research entitled "Oil Curse" and emphasized on GDP level instead of growth rates (for each predetermined period) and showed that vast oil resources or minerals will not lead to long-term economic growth reduction. On the other hand, the negative effect of unprecedented wealth resulted from the resources on the institutions, as discussed in common literature, would rise from the fact that we consider the primary GDP level as our base.

Poelhekke and Ploeg (2007) carried out a study entitled: "fluctuation, financial development and natural resource curse" and showed that resource curse has been much more serious in countries where there have been many ethnic, religious, and language minority groups.

Barbier and Edward (2007) did a study on "borderlines and consistent economic development" and reasoned that borderline exploitations of natural resources can lead to inconsistent development and its outstanding features are boom and stagnation cycles along with permanent low income levels in long-term.

Mehlum and et al (2006) carried out a research entitled: "institutions and resource curse" and found out that good institutions can change curse into goodness.

Countries enriched with natural resources have had different experiences regarding economic growth and this is a puzzle in itself that has been posed for some countries (Gelb, 2011). Therefore studying the impact of natural resource abundance on economic 
growth is necessary and inevitable.

The goal of the present research is to find out about the phenomenon called resource curse and to study different strategies to affect natural resource abundance on economic growth and development. Accordingly, the following hypotheses were posed here:

$>$ In developed countries, natural resource abundance has had a positive effect on economic growth.

$>$ In developing countries, natural resource abundance has had a negative effect on economic growth.

(Natural resource abundance would only affect economic growth negatively only when there are weak institutions).

\section{Methodology}

The data in the present study were extracted from the data in the center of international comparisons in Pennsylvania University and Global Bank data regarding natural capital and wealth of the nations. The economic measurement model utilized to investigate about the effect of natural resources and institutions on economic growth was as follows:

$G_{i t}=X_{i t}^{\prime} \alpha+\beta_{1} T N R R_{i t}+\beta_{2} I N S T_{i t}+\beta_{3}\left(T N R R_{i t} \times I N S T_{i t}\right)+\varepsilon_{i t}$

Where, $G$ represents average yearly growth rate for GDP, $\mathrm{X}$ is a vector of control variables including primary per capital GDP level $\left(\mathrm{L}_{\mathrm{y}}\right)$, investment (ki), price for consumer level (pc), average yearly total schooling (ayts), and business freedom and all these variables hae been used in the model in the form of three year non-congruent average (based on the method described for $G$ ). TNRR represents the measurement for natural resource abundance and INST is considered as institutional quality measurement factor. Also TNRR * INST represents the interaction between natural resources and institutional quality.

Considering the theoretical foundations of this model and the variables introduced, the research model was investigated in two groups of countries (including 22 developed countries [Australia, Ostrich, Belgium, Canada, Denmark, Finland, France, Germany, Greece, Ireland, Italy, Japan, Netherland, New Zealand, Norway, Portugal, Spain, Sweden, Switzerland, Turkey, England, America, and International money fund (2012)] and 61 under-developed and developing countries) for the time period between 1996 and 2010. For both groups of countries first we used meaningfulness test of the group effects to recognize the nature of data (pooled or panel data) and Brush-Pagan and Haussmann tests to recognize the difference we utilized fixed effects and random effects. Then, the research model was estimated using fixed effects method.

\section{Results}

The results of model estimation for each of the groups were as follows:

\section{- Advanced (Developed) countries}

\section{(A) The meaningfulness of group effects test}

Based on table (1), the results of the test showed that in an assurance level of 95 percent, 
the null hypothesis claiming the surplus nature of the foxed effects has been rejected and therefore the meaningfulness of fixed effects is approved.

Table (1): Fixed effects meaningfulness test

\begin{tabular}{|l|c|c|}
\hline & $\mathrm{F}$ & $\mathrm{P}$ \\
\hline $\mathrm{F}$ test showing that all $\mathrm{u}_{\mathrm{i}} \mathrm{s}$ are equal to zero & 5.92 & 0.00 \\
\hline
\end{tabular}

\section{(B) Brush-Pagan test}

As the results of estimates have shown, we could not reject the null hypothesis of BrushPagan test (the variance between intersections is equal to 0 ). In other words, there is not any conviction that there is not a meaningful difference between countries (table 2).

Table (2): Random effects meaningfulness test

\begin{tabular}{|l|c|c|}
\hline & $\mathrm{X}^{2}$ & $\mathrm{P}$ \\
\hline $\operatorname{Var}\left(\mathrm{u}_{\mathrm{i}}\right)=0$ test & 0.35 & 0.55 \\
\hline
\end{tabular}

\section{(C) Haussmann test}

As the results of Haussmann test have represented the null hypothesis claiming that $\mu_{\mathrm{i}} \mathrm{s}$ (the history of each individual or intersection) will not condition the independent variables and are independent of them could not be rejected. Therefore, estimation using fixed effects method is more efficient (table 3).

Table (3): Haussmann test to select between fixed effects or random effects

\begin{tabular}{|l|c|c|}
\hline & $\mathrm{X}^{2}$ & $\mathrm{P}$ \\
\hline $\mathrm{H}_{0}$ : There is no difference between systematic coefficients. & 154.33 & 0.00 \\
\hline
\end{tabular}

According to the results gained in table 4, the signs of estimation coefficients are based on the theoretical foundations. For example, the estimation coefficient for investment (in the form of a proportion of GDP for real per capita) showed that whenever investment increases $1 \%$, the average yearly growth rate of GDP (real per capita) will increase relatively about 0.38 percent, or the estimation for business freedom showed that if business freedom increases $\% 1$, it could be expected that the average yearly growth rate of GDP will increase about \%5.71. Of course, $t$ statistic showed that in an assurance level of $\% 95$ (or a meaningfulness level of $\% 5$ ), the indexes of human capital, institutional quality, natural resource abundance, natural resources interaction, and institutional quality did not have a meaningful effect on growth, although the sign of their estimation coefficients accords with the theory (maybe this is mainly rooted from the type of countries elected, their composition in the sample, and their different institutional frameworks). On the other hand, F statistic showed that the regression has been meaningful (all estimation coefficients in the model have been counter to zero meaningfully). 
Table (4): Economic growth regression

\begin{tabular}{|l|c|}
\hline Dependent variable: Average yearly growth rate of GDP & \\
\hline Latitude from base & $78.11(6.03)$ \\
\hline Primary per capita domestic gross product (start of the period) & $-11.98(-8.31)$ \\
\hline Investment & $0.38(6.59)$ \\
\hline Consumer price level & $-0.0065(-0.06)$ \\
\hline human capital & $0.18(0.06)$ \\
\hline Business freedom & $5.73(4.11)$ \\
\hline Natural resource abundance index & $5.18(1.35)$ \\
\hline Institutional quality & $17.04(2.26)$ \\
\hline Interaction between natural resources and institutional quality & $-6.51(-1.38)$ \\
\hline $\mathrm{R}^{2}$ & 0.24 \\
\hline Sample volume & 110 \\
\hline F & 22.52 \\
\hline
\end{tabular}

*The numbers within the parentheses represent t White statistic.

\section{- Underdeveloped and developing countries}

The results of group effects' meaningfulness tests, Brush-Pagan and Haussmann tests for underdeveloped and developing countries were as follows:

(A) Group effects meaningfulness test

Test results showed that in an assurance level of 95 percent, the null hypothesis claiming that fixed effects were surplus was rejected and therefore the meaningfulness feature of fixed effects was approved (table 5).

Table (5): Fixed effects meaningfulness test

\begin{tabular}{|l|c|c|}
\hline & $\mathrm{F}$ & $\mathrm{P}$ \\
\hline $\mathrm{F}$ test showing that all $\mathrm{u}_{\mathrm{i}} \mathrm{s}$ are equal to zero & 1.83 & 0.00 \\
\hline
\end{tabular}

\section{(A) Brush-Pagan test}

As the results of estimates have shown, we could not reject the null hypothesis of BrushPagan test (the variance between intersections is equal to 0 ). In other words, there is not any conviction that there is not a meaningful difference between countries (table 6 ).

Table (6): Random effects meaningfulness test

\begin{tabular}{|l|c|c|}
\hline & $\mathrm{X}^{2}$ & $\mathrm{P}$ \\
\hline $\operatorname{Var}\left(\mathrm{u}_{\mathrm{i}}\right)=0$ test & 0.67 & 0.41 \\
\hline
\end{tabular}

\section{(B) Haussmann test}

As the results of Haussmann test have represented the null hypothesis claiming that $\mu_{\mathrm{i}} \mathrm{s}$ (the history of each individual or intersection) will not condition the independent variables and are independent of them could not be rejected. Therefore, estimation using fixed effects method is more efficient (table 7).

Table (7): Haussmann test to select between fixed effects or random effects

\begin{tabular}{|l|c|c|}
\hline $\mathrm{H}_{0}$ : There is no difference between systematic coefficients. & 33.67 & $\mathrm{P}$ \\
\hline
\end{tabular}


According to the results gained in table 8, the signs of estimation coefficients are based on the theoretical foundations. For example, the estimation coefficient for investment (in the form of a proportion of GDP for real per capita) showed that whenever investment increases $1 \%$, the average yearly growth rate of GDP (real per capita) will increase relatively about 0.03 percent, or the estimation for business freedom showed that if business freedom increases $\% 1$, it could be expected that the average yearly growth rate of GDP will increase about \%3.68. Of course, $t$ statistic showed that in an assurance level of $\% 95$ (or a meaningfulness level of \%5), the indexes of human capital, institutional quality, natural resource abundance, natural resources interaction, and institutional quality did not have a meaningful effect on growth, although the sign of their estimation coefficients accords with the theory (maybe this is mainly rooted from the type of countries elected, their composition in the sample, and their different institutional frameworks). On the other hand, F statistic showed that the regression has been meaningful (all estimation coefficients in the model have been counter to zero meaningfully).

Table (8): Economic growth regression

\begin{tabular}{|l|c|}
\hline Dependent variable: Average yearly growth rate of GDP & \\
\hline Latitude from base & $23.61(2.35)$ \\
\hline Primary per capita domestic gross product (start of the period) & $-5.25(-4.10)$ \\
\hline Investment & $0.03(6.59)$ \\
\hline Consumer price level & $-0.02(-2.67)$ \\
\hline Human capital & $0.75(1.87)$ \\
\hline Business freedom & $3.68(3.67)$ \\
\hline Natural resource abundance index & $-0.05(0.09)$ \\
\hline Institutional quality & $3.21(0.59)$ \\
\hline Interaction between natural resources and institutional quality & $0.18(0.88)$ \\
\hline $\mathrm{R}^{2}$ & 0.17 \\
\hline Sample volume & 305 \\
\hline F & 6.12 \\
\hline
\end{tabular}

*The numbers within the parentheses represent $t$ White statistic.

\section{Discussion and Conclusions}

The realization of natural resources abundance in the form of resource curse deals with a very important and challenging economic question and it is as follows: why some countries have high growth levels meanwhile some others suffer from stagnation? The practical result of finding the answer to such questions and also the recognition of methods trough which the unprecedented wealth of economic growth resources are delayed can be considerable specifically if the science is going to be directed towards transparent policy making advice for the host governments and internationally supportive institutions. However, the research literature shows that resource curse phenomenon is inevitable. Countries enriched with natural resources and have access to good institutions, business freedom, and high investments in discovering technologies can enjoy the benefits of natural resources' wealth. In other words, the final conclusion of several different structures of effectiveness of natural resources does not mean that 
the need to minerals' wealth necessarily does not lead to economic or political underdevelopment through the use of many of such strategies. In return, it would be better to consider resource abundance as two sided coin that has both advantages and risks following them. As much as it can be spent for unnecessary things, the optimal utilization of it can put forwards countless advantages (Lederman \& Maloney, 2008; Van der ploeg, 2011). For any country the priority should be to recognize methods to avoid risks that have troubled other producers of minerals in the past and also the efforts and moves to find out success routes are highly appreciated. In the present research some of the most important strategies of the effectiveness of natural resources have been investigated. The most important ones were as follows: first, Purbish-Singer theory claiming that negative long-term trend in goods price based on theoretical foundations representing the presence of positive trend and the practical findings showing that adjustment trend does not exist in both sides were rejected. But there are five other strategies that refer to objective realities.

(1) Goods price fluctuation is high and it follows with risk and trading costs, (2) appropriation of natural resources and if it leads to make industry sector smaller and due to the positive external effects of industry section, it can harm growth, (3) the benefits of raw materials lead to aggressive institutions and wave launchers and some of major effects of it are corruption, inequality, hierarchical structure, and lack of lawful governance. On the other hand, countries that benefit from natural resources, are opt to encounter armed clashes. Also the lack of ownership laws can strengthen the incentives to rapidly evacuate natural resources and this will force future generations to face the problems, (5) Netherland disease that arises from goods' supply requires to increase real money value and to increase governmental expenses. Both cases develop non business goods and service sections (such as house) and lead to smaller section of industry. On the other hand, when global prices for the goods collapse, its adjustment would most often be difficult due to the expenses and inflation debts of the government and inflated government liabilities and also the smaller industry sector.

On the other hand, the estimated model in the present study for 83 countries and during the time period between 1996 and 2010 (based on current data and their quality) could not represent the meaningful effects of institutions on the growth and its detrimental role in changing curse into advantage (the rejection of all research hypotheses). Therefore, there is still a need for further research using different samples (changing the combination of the countries present in our sample) and the model should be estimated using other indexes to measure natural resources abundance.

Thus, the analysis of countries rich with resources including areas such as macroeconomics, public finance, public politics, international economics, resource economics, economic history, and applied economic measurement. Additionally, the analyses of this area of knowledge exploits from the cooperation of political science scholars and economic history recorders. Also, regarding the evidences proposed we need more research to identify the changing role of institutions throughout the history. Also to understand the issue that why resource curse has emerged as a phenomenon within the last four to five decades, while before that the natural resources were serving to enhance the growth (Van der ploeg, 2011; Frankel, 2012). 


\section{References}

Abrahamian, Yervand (2008). Modern Iran history. Translated by Ebrahim Fattahi (2010), Nashr-e-Nei Publications, Tehran.

Landes, Davis (1999). Wealth and poverty of nations; why some are so wealthy and some are very poor? Translated by Nasser Movaffaghian (2005), Higher Education Social Security Research Publications, Tehran.

Alexeev, Michael, and Robert Conrad, 2009, "The Elusive Curse of Oil," Review of Economics and Statistics, 91: 586-98.

Acemoglu, Daron, and James A Robinson, 2011, Why Nations Fail: The Origins of Power, Prosperity, and Poverty, Crown Publishers, New York.

Acemoglu, Daron, Simon Johnson, and James A Robinson, 2005, "Institutions as a fundamental cause of long-run growth. Ed. Philippe Aghion and Steve Durlauf' Growth Lakeland 1: 385-472.

Auty, Richard, 2007, "Patterns of Rent-Extraction and Deployment in Developing Countries: Implications for Governance, Economic Policy and Performance," in G. Mavrotas and A. Shorrocks, editors, Advancing Development: Core Themes in Global Economics (Palgrave: London), pp.555-577.

Barbier, Edward, 2007, "Frontiers and Sustainable Economic Development," Environmental and Resource Economics, 37:271-295.

Barro, Robert and Jong-Wha Lee, 2010, "A New Data Set of Educational Attainment in the World, 19502010,” NBER Working Paper No. 15902.

Easterly, William, and Ross Levine, 2003, "Tropics, Germans and Crops: How Endowments Influence Economic Development," Journal of Monetary Economics 50, no. 1, 3-39.

Frankel, Jeffrey, 2012, “The Natural Resource Curse: A Survey,” Beyond the Resource Curse. Ed. Brenda Shaffer and Taleh Ziyadov. Penn Press, 2012.

Gelb, Alan, 2011, "Oil for Uganda - or Ugandans? Can Cash Transfers Prevent the Resource Curse?” Center for Global Development Working Paper 261, July.

Lederman, Daniel, and William Maloney, 2008, "In Search of the Missing Resource Curse," Economia 9, no. 1, Fall.

Mehlum, Halvor, Karl Moene, and Ragnar Torvik, 2006, "Institutions and the Resource Curse," Economic Journal 116, 508, 1-20.

Poelhekke, Steven, and, Frederick van der Ploeg, 2007, Volatility, Financial Development and the Natural Resource Curse," CEPR DP6513, October. online: http://www.oxcarre.ox.ac.uk/images/stories/papers/ResearchPapers/oxcarrerp200803.pdf

Van der Ploeg, Frederick, 2011, "Natural Resources: Curse or Blessing?" May. Forthcoming, Journal of Economic Literature, 49: 366-420. 